\title{
MILGRAM'S EXPERIMENT AND GENDER BIASES IN INDIAN CONTEXT
}

VISHIST SRIVASTAVA | PRAKHAR RAJ

INDIAN INSTITUTE OF MANAGEMENT, INDORE 


\section{ABSTRACT}

Across every area of our culture, the distinction between influential people and those below them is normal. There are figures of authority who conduct duties every day for us, and yet we are also lazy. In this paper, participants face the same order but of two distinct individuals-figures of authority or ordinary citizens-to test the difference in responses. The responses when the authority figure is specific are also checked. We seek to get the common public to address figures of authority in the Indian sense. Individuals appear to be more likely, without any proof or test, to obey certain rules and submit to certain individuals.

This paper will bring out the biases and change in behaviour of people, when encountered with authority figures, but of different genders.

Keywords: obedience, authority, gender roles 


\section{INTRODUCTION}

We face a host of decisions every day from a number of sources. This is interesting to many individuals and does not always have a straightforward response how we sort good from bad and useful from useless. We take on a different position in the face of authority. Historically, we are molded to some degree to distrust authority and seek to attain positions of power, to make us less sensitive.

The definition of obedience says that a person would not have done so without such an order. We are always unaware of the tasks that have been given to us, so we believe that adequate deliberation has been given to us. We might also argue that the willingness of the common people to make their choices is weak in the face of authority.

Clearly, obedience provides clear benefits. It is necessary to instill correct discipline values in young children and to comply with the rules and regulations. Respect is often won and greater ambitions are necessary to become figures of authority. Most importantly, adherence to the hidden laws of daily relationships will make us happier in the long run.

However, it often may lead to serious consequences by simply supporting authority as is the case with Milgram's experiment. When instructed, participants were asked to give helpless victims lethal shocks. This was a classic experiment that intrigued us because the negative side of obedience was a radical move. The amount of time people would spend sacrificing universal principles to simply obey authority is troubling. 
Our experiment tests the effect authority figures have on common people. We do not vary the instructions but who gives and to whom the instructions are given. Our hypothesis revolves around finding if the same task, when presented to people by both an authority figure and a non-authority figure, has the scope to show varying responses from the participants or not. Additionally, we want to test responses when the gender of the authority figure is changed. Our Dependent Variable, DV, is the response towards authority. Our Independent Variables, IVs, are the presence of an authority figure and gender of the authority figure.

We want to understand a more complex problem which recognizes not only hierarchy and authority as commonplace in the culture, but also how individual states of mind shift with perceived "legitimate" figures. The research will also help us determine how strongly an instrument authority affects others and how to benefit from that. Our study also analyzes how responses change based on other social factors such as gender.

\section{Research Questions}

- Does the presence of an authority figure affect the response of the subject to an instruction?

- Does the gender of the authority figure affect the response of the subject to an instruction? 


\section{LITERATURE REVIEW}

1.Milgram's obedience to authority experiments: Origins and early evolution

Stanley Milgram's experiments on Obedience to authority remain one among the principal experiments in the area of psychology.

The paper consists of two parts, a two part report, showing the history and early development of Milgram's OTA experiments with insight into the previous contributions and unpublished Milgram 's personal archive records, the Sterling Memorial Library at the Stanley Milgram Papers (SMP).

The Author has shown Milgram 's understanding, especially his own curiosity about the Holocaust and his pHD thesis: it activates the intent of "creating a stronger situation of obedience" and most of the participants are following "commands" to behave aggressively towards another individual. The paper looks at how Milgram 's powerful 'incandescent moment' can redirect attention away from the group strengths on which Asch concentrated to individual behavior of social psychologists.

2. Stanley Milgram's Obedience to Authority "Relationship" Condition: Some Methodological and Theoretical Implications

In May 1962, social psychologist, Stanley Milgram, ran the maximum controversial version of his Obedience to Authority (OTA) experiments: the relationship condition (RC).

In the RC, participants had to send a mate, and one was a teacher and the other a learner. The pilot was hiddenly conscious that the experiment virtually investigates whether his friend could 
comply with the instructions of an experimenter to do him harm. The RC was only completed by $15 \%$ of the teachers. For an essay written for 1965, Milgram spoke extensively about the RC. Nevertheless, the RC was not listed in the book of 1974, and was unpublished until 1997.

If the results had been written, Milgram may have dismissed Mixon 's powerful and enduring critique in his research technique. This paper raises a big concern about the nature of the partner / trainer relationship with the trainer. In other words, if it was necessary to have a link between the subject and the learner, what sort of results might have been obtained from the Obedience Style experiment in which the patient is an alien.

Mixon stressed that only experts can grasp 'the ever-growing wider sections of society and physical life' and that when decisions are taken that are either responsible for some public opinion or for certain attitudes towards figures of authority, the public should not concentrate on the nuances of such relations.

3.Milgram's Obedience to Authority Its Origins, Controversies, and Replications

The obedience to authority theory of Milgram was published fifty years ago. It became the subject of the debate on social and behavioral science ethics. A comprehensive description of both is included in this article. -- Milgram and its leader, Baumrind, were written from a social comportement rather than a metaphysical technology. For example, in 1953, Milgram tried to comply with the extremely ambiguous ethics rules of the APA. Ethics was a regulative operation. Replications of 1966 showed that healthcare nurses have been affected in order by physicians to administer a drug and replication truncated under IRB authorisation in 2009. Milgram 's analytical power is limited by theoretical weakness, Mixon argues, and says he ought not to have used ambiguity to ensure that the harm of some sort or any other which could have led to 
disobedience was certain. Nonetheless, there has been a degree of ambiguity in the issue of whether or not participants will proceed.

\section{QUANTITATIVE RESEARCH}

\section{METHODOLOGY}

We have performed a field experiment in order to address our study questions. We have divided the experiments into two categories, which were sub-categorized according to the scenarios required to evaluate the respondents' actions. Obedience can be defined as a type of social control in which a person reacts to an order by a person who is mostly a figure of authority. We decided to explore how different situations differed.

With this experiment, we propose a relationship between authority and obedience, whereby gender variables will also be included, and how they are linked and correlated. We carried this experiment on a market to limit the opportunities for inclusion so that we could get a general public 's answers and a general overview of society.

For imitating an authority figure during the course of our experiment we wore a green fluorescent vest that was generally worn by construction workers/traffic patrol.

We divided the experiment into the following categories:

- A - Standard experiment to determine the effect of perceived authority

○ A1 - Without Authority

A2- With Authority

- $\quad \mathrm{B}-$ Bringing gender into the experiment

○ B1 - Authority Female - Subject Female

○ B2 - Authority Female - Subject Male 


\section{○ B3 - Authority male - Subject Female \\ ○ B4 - Authority Male - Subject Male}

In Experiment A, one volunteer from the group turned to mimic an authority figure and a civilian in different areas of the market who provided random instructions. The instruction said, "You can't stay here. Please leave. Please leave. The English language was used throughout the experiment. Our goal was to determine whether the respondents followed the instructions immediately or chose to question or reject the instructions. A total of ten men, five in each case, came from our party.

One male and one female member imitated figures of authority (not at the same time) for experiment $\mathrm{B}$. The instruction and the delivery language remained the same as the previous experiment in this area. The two leaders came to five separate men and women from both sexes. Thirty participants provided the total sample size for our experiment. The goal was the same as it was before.

We took care to ensure that the general public didn't get an idea of what we were doing by constantly moving around.

We have used the above method because we wanted to make the experiment more participatory and impartial. We also might have also used a survey approach, but we performed a field experiment because of the collaborative and spontaneous aspect of the experiment.

We have also worked upon the correlation and causation for the results that we have found. We have used MS Excel to run a regression model for the same. 


\section{RESULTS}

\begin{tabular}{|l|l|}
\hline Experiment & Observations \\
\hline A1 & 2 out of 5 followed the instructions \\
\hline A2 & 4 out of 5 followed the instructions \\
\hline B1 & 4 out of 5 followed the instructions \\
\hline B2 & 2 out of 5 followed the instructions \\
\hline B3 & 4 out of 5 followed the instructions \\
\hline B4 & 3 out of 5 followed the instructions \\
\hline
\end{tabular}

\section{ANALYSIS}

\section{Experiment A:}

We assigned value 1 to authority involvement and value 0 to lack of authority. When the respondents followed the instructions without query, we assigned 1 to the instances, and when the respondents asked for the instructions, we assigned value 0 to the case.

\section{Experiment B:}

We assigned the value 1 to the female authority figures and the value 0 to the male authority figures. We assigned the value 1 to the female respondents and the value 0 to the male respondents. We assigned the value 1 to the instance when the respondents followed the 
instructions without question and the value 0 to the instances when the respondents questioned the instructions.

\section{DISCUSSION}

We attempted to run a regression analysis for the findings. The regression equation for Experiment $\mathrm{A}$ is as follows:

$\mathrm{DV}=0.4+0.4$ (Authority's presence)

For the authority figure's presence, POA was assigned with value 1 and hence the value of DV increases, which means that respondent complied to the instruction given to them.

The regression equation for Experiment $\mathrm{B}$ is as follows:

$\mathrm{DV}=0.55-0.1$ (Authority's gender) +0.3 (Respondent's gender)

Inferences drawn from the experiment:

Answers are more inclined for a female leader to obey a male dominant figure's orders. Women interviewed are more likely than men to obey instructions from a source of authority.

Not only do our findings contradict the case advocated by past studies in this field, but it also indicates that the relation between authority and obedience remains the same in the Indian context despite India's very different cultural and social practices to that of the West. Our study also aims to fill the void in the variables which may affect the degree of obedience in interviewees by emphasizing the sex of the participant and the interviewees. The findings of the research demonstrate strongly that in this aspect of compliance there are possibilities for future practice. 


\section{QUALITATIVE RESEARCH}

\section{Thematic analysis:}

Post-experiment we attempted to interview the participants about their experience and what made them take certain decisions while encountering the authority figures. Participants were not expecting it as an experiment and were glad to know that they were being experimented. We didn't let them know about the details of the experiment but, let them figure out, how exactly they process the information/instructions being given to them. We also tried to look if the experiment also affected the participants' decision making process.

The interview was conducted based on following questions-

- What was your perception towards authority figures, when they instructed you to do something?

- Did the gender of the person affect your decision?

- How do you generally look at the authority figures?

- Do you think Authority figures can influence you easily?

We adopted the deductive approach and came to the data having a set of preconceived themes in mind.We classified these interviews into four categories depending on their gender and their respective response and these were as follows:

1. Male-Male interaction (rejection) [B4 - Authority Male - Subject Male]

2. Male-female interaction (rejection) [B3 - Authority male - Subject Female]

3. Female-Male interaction (rejection) [B2 - Authority Female - Subject Male]

4. Female-Female interaction (rejection) [B1 - Authority Female - Subject Female] 
We did not take the cases of obedience to authority as they confirmed our hypothesis in the first place.

\section{THEMES FOUND IN THESE INTERVIEWS}

\section{- Male-Male interaction}

The first and foremost theme we found out was the lack of official documentation or signs anywhere in the vicinity that would allow the subject to trust the experimenter. The main point of contention was the lack of any official airs about the person.

According to them, they needed a valid proof/evidence of why exactly they had to follow the instructions. Most of them clearly mentioned that without knowing the reason for certain instructions, they would not follow the orders. A few of the participants went to the extent of calling the authority figures to be dominating, and they didn't want to agree to them. The participants who called authority figures to be dominating also mentioned that they didn't want to adhere to orders which were not verified. According to these people authority figures cannot influence them easily.

\section{- Male-Female interaction}

The respondents were said that they were surprised to see a woman worker asking them to move when in normal situations, only men workers have ever talked to them. The main underlying theme was one which proved that males did not trust females to be in positions of power. According to them, it was difficult for them to agree to a woman worker without prior verification. It would have been more agreeable if there was some hoarding available which could confirm that there is some construction work going on. Participants also said that the position required a dominating person and men would have done that better. They don't feel to be influenced by authority figures at all. 


\title{
- Female-Female interaction
}

The same theme ran through that even women did not expect women to be out on the front lines and being in power. They said that women don't generally come to talk to people and it was men in scenarios like these that talked the most. They do feel influenced by the authority figures but, seeing a woman in place made them doubtful.

\section{- Female-Male interaction}

\begin{abstract}
Again, the theme of the absence of any form of official documentation. The reason was that in the absence of signs, notices etc, it was hard to trust the man. Another reason was their perceived notion of the man not being assertive enough. According to them, they have learned that men most of the time, approach them and try to disturb them, and they don't care about such people anymore. If no verified source tells them to obey certain rules, they could not obey them. Most of them needed a verified source to believe in the authority figures.
\end{abstract}




\section{FUTURE DIRECTIONS/RECOMMENDATIONS}

While our sample size was not adequate to provide definitive evidence, it gave us interesting inferences. The results were adequate to demonstrate that the theory holds a much greater capacity to be examined. In our work we also thought that the language in which the instructions were supplied should be applied to the equation, as possible variables.

This hypothesis indicates that people are more sensitive, for example, to people who represent authority, than to a construction worker (the basis of our study). People might respond well to a police officer. In particular, people do not know how to give up their power, making it difficult to remember to step up and make an alternative strategy. For many of us it seems very likely that "the boss" will not obey the leader or obey him in power as though it were, and people do not want to follow the leader.

Discapacity through home and school is so deeply rooted in us that the implications are now within. Someone should punish us more, we struggle when we criticize those in power for the presumption that we really count. We are terrified we will be seen as disrespectful, taking too much time or resources. In short, rather than direct consequences, we fear lack of acceptance and shame.

But, a startling discovery has come to mind as well. People tend to follow male authority figures more than female authority figures. Patriarchal regimes have established that men determine in society and occupy and are deemed dominant positions of power and responsibility. Men are the builders of laws, and women are the adherents of law. This authority should never be challenged because if it does, the price is payable. The main definition is representative of both men and women 's conventional roles of sex. The employees must challenge the authority of a woman and obey a man blindly. The most common mixture of power and dominant roles is with men rather than women.

In historical terms, authority has been spread equally across genders irrespective of the inadequate representation of women as CEOs in Fortune 500 corporations or Congress. People 
prefer to think of men as masterful, optimistic and responsible individuals. They consider women to be communal, accessible, friendly and caring individuals. They think leaders are more masterful, more trustworthy, more efficient, more confident and more task driven.

Regarding women, there is both a dual norm then a double bind. The double norm allows women to prove that they can take responsibility, which is rarely a problem for men. The double bind is that the blowback women take control of the pot. They 're said to be tough and solid. In the case of women in authority they had to behave like men in order to be understood and to use very similar linguistic types.

This is a problem that India has to move towards promoting women and slowly moving from a patriarchal society to a matriarchal one. Only then can India, successfully move forward from distrusting women leaders in authority to actually respecting their opinions. 


\section{REFERENCES}

McLeod, S. (1970, January 01). Saul McLeod. Retrieved from https://www.simplypsychology.org/obedience.html

Russell, N. J. (2011, March). Milgram's Obedience to Authority experiments: Origins and early evolution. Retrieved from https://www.ncbi.nlm.nih.gov/pubmed/21366616

Russell N (2014). Stanley Milgram's Obedience to Authority "Relationship" Condition: Some Methodological and Theoretical Implications. Retrieved from

https://www.researchgate.net/publication/283376676_Stanley_Milgram\%27s_Obedience_to_Aut hority_Relationship_Condition_Some_Methodological_and_Theoretical_Implications

Perlstadt H (N.D). Milgram's Obedience to Authority Its Origins, Controversies, and Replications. Retrieved from https://www.researchgate.net/publication/316559861_Milgram's_Obedience_to_Authority_Its_O rigins_Controversies_and_Replications

Nelson, A. (2009, February/March). Follow the Leader: Authority. Retrieved from https://www.psychologytoday.com/us/blog/he-speaks-she-speaks/201902/follow-the-leader-auth ority

Vos, J. D. (2009). Now that you know, how do you feel? The Milgram experiment and psychologization [Scholarly project]. In Annual Review of Critical Psychology. Retrieved 2019.

Sabini, J., \& Silver, M. (n.d.). Dispositional vs. situational interpretations of Milgram's obedience experiments:" The fundamental attribution error." 